\title{
Scrapping PHE, a threat to oral health?
}

\author{
Dr Robert Witton, Chair of the BDA Dental Public Health Committee, asks what scrapping Public \\ Health England (PHE) means for dentistry and calls for oral health not to be an optional extra.
}

\footnotetext{
$\mathrm{t}$ took us all by surprise this week [19

August] when the Government decided

to scrap Public Health England. We now know it will be replaced by the National Institute for Health Protection (NIHP). Its mission, according to Health Secretary Matt Hancock, is to protect people from threats to public health.

But what does this mean for dentistry? Weve written an open letter (https://bit.ly/2Gcv4eM) to Matt Hancock to seek urgent clarification on the place of dental public health in this brave new world.
}

\section{The threat to oral health}

Dentistry is so often forgotten in the wider scheme of things, and we've made a plea to ensure we are part of the new plan. Dental decay is perhaps not a 'threat' in quite the same way infectious diseases are, but that doesn't mean it can be put on the back burner.

Oral health inequalities were already a problem across the UK and with COVID-19, we can only anticipate those problems getting even worse. We've pointed out that many public health programmes have been suspended, and patients' access to dental care remains limited, which cannot be forgotten about. Now is the time to take some decisive action and ensure we are working in a strategic and joined-up way to ensure we can tackle oral health inequalities.

We have outlined our concerns about the potential loss and disruption to priority work areas in dental public health, especially at the local level, and the need for continuity for all of our patients, and especially those who are most vulnerable.

\section{Prevention in dentistry}

Announcing the news this week, Matt

Hancock said the government is 'passionately committed to health improvements and the prevention agenda. He also highlighted the recently announced obesity strategy and said that 'levelling up health inequalities' is very important. knowledgeable dental public health workforce must not be lost.

\section{An effective approach to oral health is needed \\ Effective management of the pandemic response is a clear national priority. But meaningfully protecting the public long-term hinges on an effective approach to public health, in which oral health is not an optional extra.}

\section{'Now is the time to take some decisive action and ensure we are working in a strategic and joined- up way to tackle oral health inequalities.'}

Prevention in dentistry lies at the heart of where we need to be - and is something that has been discussed widely over the past few years. But it does feel like now is the time to really put our money where the mouths are. We have asked the government to double down on prevention, enabling us to transform lives and save money.

We've asked what will happen to the regular oral health surveys, which help us to benchmark where we are - to see where we are doing well, and also where we need to direct more resources to help that 'levelling up' agenda.

Robust evidence is essential for us to be able to plan and guide our work. The expertise of our highly skilled and
We must bridge the gap between the local and national level, ensuring local commissioning services are being supported to deliver the services needed for their communities, backed up with real investment. Planning the future scope and scale of provision is now fundamental, given low levels of capacity across the service, which was already struggling before COVID-19.

The government has said it plans to consult on the path going forward and we will represent dentists and dentistry during these crucial discussions. The impact of COVID-19 on the ability for dentists to care for their patients is something that cannot be underestimated, and what we choose to do (or don't do) next, will impact on generations to come.

\section{Documenting the pandemic and its effect on dentistry}

In response to the COVID-19 pandemic the British Dental Association (BDA) Museum has been actively, and sensitively, researching stories and identifying objects to collect. These items will provide a permanent record for future generations of medical, cultural and personal responses to the outbreak and chronicle its impact on society.

The Museum has been collating NHS, government, BDA advice and newspaper articles but is keen to document the pandemic and its effect on dentistry through objects.
If you have any photographs, PPE equipment, health and safety equipment or signage to donate then please email museum@ bda.org. 